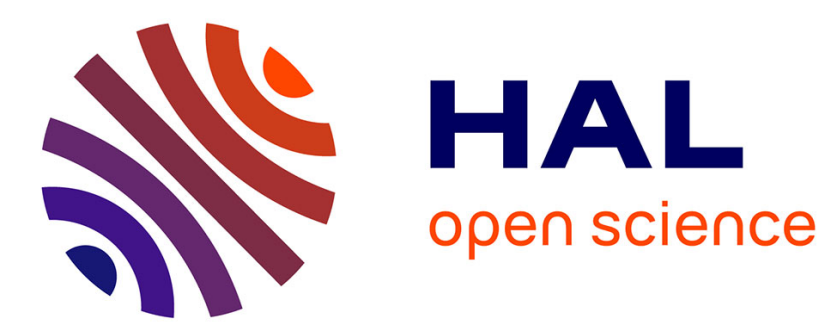

\title{
Pressure-enforced plasticity in MAX phases: from single grain to polycrystal investigation
}

\author{
Guo-Ping Bei, Antoine Guitton, Anne Joulain, Veronique Brunet, Sylvain \\ Dubois, Ludovic Thilly, Christophe Tromas
}

\section{- To cite this version:}

Guo-Ping Bei, Antoine Guitton, Anne Joulain, Veronique Brunet, Sylvain Dubois, et al.. Pressureenforced plasticity in MAX phases: from single grain to polycrystal investigation. Philosophical Magazine, 2013, 93 (15), pp.1784-1801. 10.1080/14786435.2012.755272 . hal-01501851

\section{HAL Id: hal-01501851 \\ https://hal.univ-lorraine.fr/hal-01501851}

Submitted on 7 Dec 2020

HAL is a multi-disciplinary open access archive for the deposit and dissemination of scientific research documents, whether they are published or not. The documents may come from teaching and research institutions in France or abroad, or from public or private research centers.
L'archive ouverte pluridisciplinaire HAL, est destinée au dépôt et à la diffusion de documents scientifiques de niveau recherche, publiés ou non, émanant des établissements d'enseignement et de recherche français ou étrangers, des laboratoires publics ou privés. 


\title{
Pressure-enforced plasticity in MAX phases: from single grain to polycrystal investigation
}

\author{
Guo-Ping Bei, Antoine Guitton, Anne Joulain*, Véronique Brunet, Sylvain Dubois, \\ Ludovic Thilly and Christophe Tromas \\ Prime Institute - Department of Physic and Mechanic of Materials, University of Poitiers-CNRS- \\ ENSMA, SP2MI-Téléport 2 - BP 30179, 86962 Futuroscope, Chasseneuil Cedex, France
}

\begin{abstract}
$\mathrm{Ti}_{4} \mathrm{AlN}_{3}, \mathrm{Ti}_{3} \mathrm{AlC}_{2}$ and $\mathrm{Ti}_{3} \mathrm{Al}_{0.8} \mathrm{Sn}_{0.2} \mathrm{C}_{2}$ MAX phases were plastically deformed at room temperature (RT) under gaseous confining pressure. Microstructures of as-grown and deformed samples are carefully analysed using scanning electron microscopy (SEM), atomic force microscopy (AFM) and transmission electron microscopy (TEM). It is demonstrated that high level of plastic deformation can be reached under confining gas pressure; the later suppresses the brittle failure at RT to the profit of plasticity. Multiscale characterization techniques are shown to provide a unique insight into all the scales of the plastic deformation; in particular, the effect of the mesoscale. Indeed, grain shape and orientation relative to the compression axis are shown to play a key role in the deformation process, intergranular stresses leading to a complex stress field in the polycrystalline samples. The TEM results show that dislocation activity highly depends on the grain orientation. The observation of dislocation entanglements unambiguously demonstrates that dislocations may be organized in such a configuration so that their glide in the basal plane can be hindered when deep plastic regime is reached.
\end{abstract}

Keywords: MAX phases; microstructure; plasticity; powder metallurgy

\section{Introduction}

$\mathrm{M}_{n+1} \mathrm{AX}_{n}$ phases (with $n=1,2$ or 3 ) form a class of nanolaminated ternary carbides or nitrides, with a hexagonal structure, where $\mathrm{M}$ stands for an early transition metal, A for a group $\mathrm{A}$-element and $\mathrm{X}$ for carbon or nitrogen [1-9]. In these materials, the $\mathrm{M}_{n+1} \mathrm{X}_{n}$ layers, characterized by mostly strong metallic $\mathrm{M}-\mathrm{X}$ bonds, are interleaved with A layers through weak $\mathrm{M}-\mathrm{A}$ bonds. This inherent nanolayered structure provides a unique combination of metal-like and ceramic-like properties, which have been extensively studied in the last decades. From the mechanical point of view, the MAX phases exhibit unique properties, combining the best of metals (machinability and damage tolerance) and ceramics (high stiffness and temperature resistance), as reviewed by Barsoum and coworkers $[9,10]$. Their main weakness is that they are generally brittle at low temperature, i.e. below their Brittle-to-Ductile Transition temperature which lies between $800^{\circ} \mathrm{C}$ and

*Corresponding author. Email: anne.joulain@univ-poitiers.fr 
$1000^{\circ} \mathrm{C}$. To understand their mechanical behaviour, a first model was proposed [11-14]: it relies on the earlier work of Frank and Stroh [15] and involves kink and shear bands formation and basal plane delamination leading to kinking non-linear elastic (KNE) properties, characterized by the formation of fully reversible, stress-strain hysteretic loops in the elastic regime $[16,17]$.

Concerning the elementary deformation mechanisms, most of the studies were devoted to the model material $\mathrm{Ti}_{3} \mathrm{SiC}_{2}$ : the major feature reported in deformed microstructures is the observation of perfect dislocations confined in the $\left(\begin{array}{llll}0 & 0 & 0 & 1\end{array}\right)$ basal plane, as expected due to the very anisotropic character associated to the laminated structure of the MAX phases. The dislocations easily slip in basal planes and either arrange in arrays or superimpose in successive basal planes to form walls. However, recent results have brought new insights onto the possible elementary deformation mechanisms: surface deformation around nanoindentation imprints have been characterized by Atomic Force Microscopy (AFM) in the recently discovered $\mathrm{Ti}_{3} \mathrm{SnC}_{2}$ MAX phase [18]. Slip lines have been observed around several high load indents and their associated slip planes have been deduced from the analysis of the local crystallographic orientations by electron backscattered diffraction. For some grain orientations, the second-order pyramidal slip system has been found to be activated. Furthermore, more specific dislocation behaviours such as double cross slip or dislocation reactions have been observed. Similarly, from Transmission Electron Microscopy (TEM) observations, the as-grown microstructure of $\mathrm{Ti}_{4} \mathrm{AlN}_{3}$ polycrystalline samples was revisited [19]: several features were observed in agreement with literature data on other MAX phases. However, detailed examination of the dislocation networks allowed observing original crucial elements: perfect and partial dislocation nucleation sites were evidenced while nucleation events seem to occur at inclusions or cavities. Moreover, out-of-basal-plane dislocation segments were observed both in dense walls and in isolated loose networks. Such defects may interact with basal dislocations impeding their movement through tree-forest interactions. Additionally, a recent TEM analysis of plastically deformed $\mathrm{Ti}_{2} \mathrm{AlN}$ polycrystalline sample has revealed that basal dislocations strongly interact within the grains and react to form complex networks [20]. This adds up to the idea that, like in most crystalline materials, dislocation glide may be easily reduced either by the native microstructure or during the course of plastic deformation as the dislocation landscape evolves.

Besides dislocations, Stacking Faults (SFs) are observed in numerous MAX systems such as $\mathrm{Ti}-\mathrm{Si}-\mathrm{C}, \mathrm{Ti}-\mathrm{Al}-\mathrm{C}, \mathrm{Ti}-\mathrm{Al}-\mathrm{N}, \mathrm{Ta}-\mathrm{Al}-\mathrm{C}$ and $\mathrm{Zr}-\mathrm{Al}-\mathrm{C}$. They are attributed to stacking errors in the layer sequence during the synthesis [12], i.e. to a lack of A layer [14] or to an insertion of one or several MX layers [19,21]. Until recently, SFs were not expected to be involved in deformation mechanisms based on shear by perfect dislocations gliding in the basal planes. However, detailed TEM analysis of SFs in asgrown $\mathrm{Ti}_{4} \mathrm{AlN}_{3}$ has shown that the fault vector present a component in the basal plane, i.e. a shear component [19], consistently with the work from Yu et al. [21]. Such result suggests that SFs may have to be considered in the deformation mechanisms, especially at high temperature where diffusion is possible.

On a larger length scale, e.g. at the grain scale, the micromechanism suggested to explain that KNE properties are the Incipient Kink Band (IKB) [16,17]: IKBs are parallel dislocation loops stacked one on top of another. The geometry of IKBs is such that they only remain extended if a load is applied; removal of the load results in their total annihilation. To date, direct evidence for the existence of IKBs is lack- 
ing, bearing witness to the incomplete knowledge of deformation mechanisms in MAX phases.

From this literature survey, the full knowledge of the defect structures (in as-grown and deformed materials) appears as a crucial step to overcome in order to characterize the elementary deformation mechanisms and to relate them to macroscopic features such as the brittle or ductile behaviour.

Furthermore, at the polycrystal length scale, there is no model addressing the interaction of grain families and their respective plastic strains within the course of the deformation of a MAX bulk polycrystal, although this is the common situation since most fabrication processes are based on powder metallurgy that do not result in bulk single crystals. Moreover, typical MAX microstructure evidences grains with high aspect ratio, i.e. basal plane-oriented pancake-like grains: this should be taken into account considering the response of the polycrystal; in particular, from the grain to grain load sharing point of view.

In the present paper, we are pursuing the objective of obtaining a scenario on the different steps of plastic regime and the onset of damage at Room Temperature (RT). For this, we use a very original combination of multiscale mechanical expertise (ranging from nanoindentation to macroscopic tests under confining pressure) and of microstructural characterization, including AFM and TEM, applied to the following MAX phases: $\mathrm{Ti}_{4} \mathrm{AlN}_{3}, \mathrm{Ti}_{3} \mathrm{AlC}_{2}$ and $\mathrm{Ti}_{3} \mathrm{Al}_{0.8} \mathrm{Sn}_{0.2} \mathrm{C}_{2}$.

\section{Experimental details}

Polycrystalline bulk samples of the three studied MAX phase systems have been synthesized by Hot Isostatic Pressing (HIPing).

$\mathrm{Ti}_{4} \mathrm{AlN}_{3}$ synthesis has been performed by Barsoum and co-workers [22,23] from AlN, TiN and $\mathrm{TiH}_{2}$ reactant powder mixture HIPed at $1275^{\circ} \mathrm{C}$ for $24 \mathrm{~h}$ under $70 \mathrm{MPa}$. HIPing process is followed by annealing at $1325^{\circ} \mathrm{C}$ for $168 \mathrm{~h}$. The final stoichiometry is shown to be $\mathrm{Ti}_{4} \mathrm{AlN}_{3-x}$.

To synthesize $\mathrm{Ti}_{3} \mathrm{AlC}_{2}$ and $\mathrm{Ti}_{3} \mathrm{Al}_{0.8} \mathrm{Sn}_{0.2} \mathrm{C}_{2}$ samples, powders of $\mathrm{Ti}(150-250 \mu \mathrm{m}$, $99.5 \%$ purity), $\mathrm{Al}(45-150 \mu \mathrm{m}, 99.5 \%$ purity), Sn $(2-20 \mu \mathrm{m}, 99 \%$ purity) and $\mathrm{TiC}$ $(<45 \mu \mathrm{m}, 98 \%$ purity) were selected as the starting materials. Ti:Al:1.9TiC and Ti: $\mathrm{Al}: 1.8 \mathrm{TiC}: 0.2 \mathrm{Sn}$ reactant mixtures were, respectively, used to obtain highly pure $\mathrm{Ti}_{3} \mathrm{AlC}_{2}$ and $\mathrm{Ti}_{3} \mathrm{Al}_{0.8} \mathrm{Sn}_{0.2} \mathrm{C}_{2}$ samples. It is well known that some A element is lost during powder metallurgy processing of the reactant mixture; as a consequence, either ( $\mathrm{Ti}$ $+\mathrm{C})$ sub-stoichiometry or $(\mathrm{Sn}+\mathrm{Al})$ over-stoichiometry is generally used. The different reactant mixtures used for ternary carbide synthesis were ball-milled in a Turbula mixer to obtain homogenous powder mixtures, and cold-compacted using a uniaxial press. The resulting cylindrical green samples $(12 \mathrm{~mm}$ in diameter and $10 \mathrm{~mm}$ in height) were sealed under vacuum into Pyrex containers, placed in a HIP chamber and subjected to the following temperature and pressure cycle:

- heating at $1450{ }^{\circ} \mathrm{C}$ with a heating rate of $30^{\circ} \mathrm{C} / \mathrm{min}$ under an $\mathrm{Ar}$ room pressure (RP),

- pressurization at $0.5 \mathrm{MPa} / \mathrm{min}$ to $50 \mathrm{MPa}$ and

- once the processing temperature and pressure are reached, holding at $1450{ }^{\circ} \mathrm{C}$ for $2 \mathrm{~h}$ and $50 \mathrm{MPa}$ for $1 \mathrm{~h}$ before cooling to RT and RP. 
After HIPing, samples were machined to remove the encapsulating glass container and sliced using a diamond wheel. Samples were thus ground using silicon carbide paper and then, polished with a diamond suspension. Finally, in order to produce a very flat surface suitable for Scanning Electron Microscopy (SEM) and AFM observation of surface deformation, a chemo-mechanical polishing (CMP) was performed using colloidal polishing slurry. Compared to conventional grinding, the CMP process avoids introducing work hardening that would modify the surface deformation behaviour.

Uniaxial compression tests were performed in the Paterson apparatus [24,25] at RT under an argon confining pressure of $350 \mathrm{MPa}$ at a strain rate of $5 \times 10^{-5} \mathrm{~s}^{-1}$. Deformation under confining pressure requires samples cut into parallelepipeds with typical size $3 \times 3 \times 8 \mathrm{~mm}$. All faces were carefully mechanically polished and inserted into fully annealed aluminium cylinders to fit into the deformation assembly of the compression apparatus. After deformation, the samples were removed from Al jackets for observation of the deformed surfaces (SEM and AFM) and TEM analysis.

Because the samples are inserted in Al cylinders, the mechanical data that are recorded during the tests are the results from both sample and Al. To remove the contribution of the Al jacket, a procedure has been developed [26]. It consists, in preliminary, tests on pure Al samples in identical conditions as the 'sample $+\mathrm{Al}$ ' tests. The obtained stress-strain Al curve is then subtracted from the 'sample + Al' mechanical data following a Rule Of Mixture (ROM) that takes into account the sample and Al volume fractions. The validity of the ROM law is conditioned to the fact that the two phases, sample and $\mathrm{Al}$, are tested in parallel without interactions at interfaces and they obey to iso-strain conditions: the ROM validity has been verified by finite elements modelling of the compression tests under hydrostatic pressure [27]. In addition, the stiffness of the compression apparatus has been taken into account. As a consequence, the mechanical properties of MAX samples are obtained in the form of stress-strain curves as reported in Figure 3, where the engineering stress $\sigma$ is plotted vs. engineering strain $\varepsilon$ at RT (the presented curves exhibit some noise associated to the very low strain rate).

The microstructure of the samples, before and after deformation, was observed by SEM (JEOL 5600LV), coupled with energy-dispersive X-ray spectroscopy (EDXS) (Oxford Isis 300) for the chemical analysis.

Surface topography on deformed samples has been investigated by AFM using a Dimension 3100 from Bruker, in tapping mode. Images have been then processed with the image analysis software WSxM [28].

Thin foils for TEM observations were prepared by a slow mechanical polishing down to $20 \mu \mathrm{m}$ prior to being argon ion thinned with a Precision Ion Polishing System from GATAN. For observation of the deformed microstructure, deformed samples were cut at $45^{\circ}$ degrees from the compression axis and then, polished with the same procedure as the as-grown material. Microstructure analysis was performed using weak beam technique and extinction diffraction condition technique on a JEOL 200CX microscope operating at $200 \mathrm{kV}$.

\section{Results}

\subsection{Observation of as-grown materials}

Figure 1a and b shows SEM micrographs in backscattered mode of the samples HIPed from Ti:Al:1.9TiC and Ti:Al:1.8TiC:0.2Sn reactant mixtures, respectively. One can 



Figure 1. The SEM images of (a) $\mathrm{Ti}_{3} \mathrm{AlC}_{2}$ and (b) $\mathrm{Ti}_{3} \mathrm{Al}_{0.8} \mathrm{Sn}_{0.2} \mathrm{C}_{2}$ as-grown samples.

observe the lamellar nature of MAX phase grains (grey areas) with an average dimension in the range $50-100 \mu \mathrm{m}$ in length and $10-20 \mu \mathrm{m}$ in width for both samples. Smaller lamellas are also observed in the grain boundaries of the sample synthesized from Ti: $\mathrm{Al}: 1.8 \mathrm{TiC}: 0.2 \mathrm{Sn}$ reactant mixture.

The EDXS analyses performed on different lamellas show that the mean Ti/Al mole ratio is 2.96 which confirm the composition of the $\mathrm{Ti}_{3} \mathrm{AlC}_{2}$ MAX phase starting with Ti:Al:1.9TiC reactant mixture. From $\frac{T i}{A l+S n}=3.01$ and $\frac{A l}{S n}=3.94$ mean mole ratios determined by EDXS on different lamellas, one can deduce that when $\mathrm{Sn}$ is introduced, the chemical composition of the resulting solid solution is $\mathrm{Ti}_{3} \mathrm{Al}_{0.8} \mathrm{Sn}_{0.2} \mathrm{C}_{2}$.

The EDXS analyses coupled with SEM observations reveal the presence of $\mathrm{Ti}_{x} \mathrm{Al}_{y}$ intermetallics (black areas) at MAX phase grain boundaries for both samples. Image analysis, performed using the imageJ software, gives a volume content of $\mathrm{Ti}_{3} \mathrm{AlC}_{2}$ 



Figure 2. (colour online) The TEM observation of as-grown $\mathrm{Ti}_{3} \mathrm{Al}_{0.8} \mathrm{Sn}_{0.2} \mathrm{C}_{2}$ sample showing typical characteristic defects: (a) dislocation piles-ups and (b) SFs.

higher than $99 \%$. About 2 vol.\% $\mathrm{Ti}_{x} \mathrm{Al}_{y}$, using independently, the image J software and the Rietveld refinement method, is measured in the $\mathrm{Ti}_{3} \mathrm{Al}_{0.8} \mathrm{Sn}_{0.2} \mathrm{C}_{2}$ solid solution.

As reported in [2], the $\mathrm{Ti}_{4} \mathrm{AlN}_{3-x}$ sample resulting from a post HIPing annealing at $1325^{\circ} \mathrm{C}$ for $168 \mathrm{~h}$ is mainly composed of $\mathrm{Ti}_{4} \mathrm{AlN}_{3-x}$, but it also contains small amounts of TiN (1-3 vol.\%) and $\mathrm{Al}_{2} \mathrm{O}_{3}$ (1-2 vol.\%). Lamellas are also observed with a dimension in the range $10-40 \mu \mathrm{m}$ in length and $5-15 \mu \mathrm{m}$ in width.

Figure 2 presents characteristic microstructure of as-grown $\mathrm{Ti}_{3} \mathrm{Al}_{0.8} \mathrm{Sn}_{0.2} \mathrm{C}_{2}$ observed by TEM. The as-grown $\mathrm{Ti}_{3} \mathrm{AlC}_{2}$ and $\mathrm{Ti}_{3} \mathrm{Al}_{0.8} \mathrm{Sn}_{0.2} \mathrm{C}_{2}$ phases present very similar microstructures characterized by two major features that are dislocations and SFs. The defect density is quite low and numerous grains or large areas are defect-free. Most of dislocations are lying in the basal plane and are organized in specific configurations: they are superimposed in different basal planes forming dislocation walls or glide in the same basal plane forming dislocation pile-ups (Figure 2a).

Figure $2 \mathrm{~b}$ shows the characteristic fringe contrast of $\mathrm{SFs}$ in $\mathrm{Ti}_{3} \mathrm{Al}_{0.8} \mathrm{Sn}_{0.2} \mathrm{C}_{2}$ observed here in two-beam condition. The SFs lie in the basal plane and always cross the whole grain. However, all SFs do not present the same contrast: some are in contrast when some are not, while dislocation contrast is more or less strong. Partial dislocations separate different $\mathrm{SFs}$ with different contrast. The as-grown $\mathrm{Ti}_{4} \mathrm{AlN}_{3}$ microstructure has been analysed in detail [19]: the characteristics are exactly the same as those observed here in $\mathrm{Ti}_{3} \mathrm{AlC}_{2}$ and $\mathrm{Ti}_{3} \mathrm{Al}_{0.8} \mathrm{Sn}_{0.2} \mathrm{C}_{2}$. It is worth noting that dislocations lying out of the basal plane are reported in as-grown $\mathrm{Ti}_{4} \mathrm{AlN}_{3}$ [19]. Their presence is not evidenced in the $\mathrm{Ti}_{3} \mathrm{AlC}_{2}$ and $\mathrm{Ti}_{3} \mathrm{Al}_{0.8} \mathrm{Sn}_{0.2} \mathrm{C}_{2}$ materials observed here.

\subsection{Deformation under confining pressure}

Figure 3 shows the engineering stress-strain curves recorded at RT in the Paterson machine; two general comments can be made: 


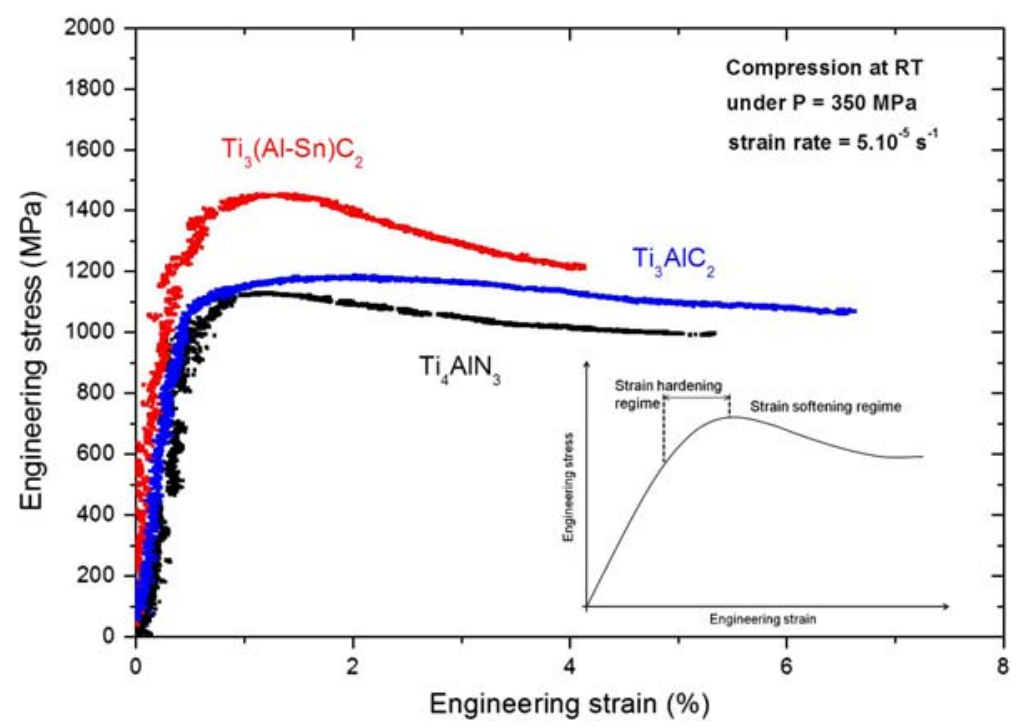

Figure 3. (colour online) Engineering stress-strain curves recorded on $\mathrm{Ti}_{3} \mathrm{AlC}_{2}, \mathrm{Ti}_{3} \mathrm{Al}_{0.8} \mathrm{Sn}_{0.2} \mathrm{C}_{2}$ and $\mathrm{Ti}_{4} \mathrm{AlN}_{3}$ samples in the Paterson machine at RT. Inset: schematic of typical MAX phase stress-strain curve identifying the strain-hardening and strain-softening regions.

- independently of the MAX phase, significant plastic strain $\left(\varepsilon_{\mathrm{p}}\right.$, between 4 and $6 \%$ ) can be imposed to the polycrystalline samples without reaching their ruin. Such result is due to the effect of the imposed hydrostatic confining pressure that artificially closes cracks to the favour of plasticity during uniaxial compression.

- independently of the MAX phase, the compression curves exhibit typical features with a linear elastic regime followed by a hardening regime (as schematized in inset of Figure 3) leading to the presence of a stress peak, $\sigma_{\mathrm{p}}$, followed by a softening leading to a zero hardening regime.

The main differences between the three tested samples are the absolute magnitude of $\sigma_{\mathrm{p}}$ and its relative magnitude compared to the zero-hardening regime: the first parameter, $\sigma_{\mathrm{p}}$, is maximum for the $\mathrm{Ti}_{3} \mathrm{Al}_{0.8} \mathrm{Sn}_{0.2} \mathrm{C}_{2}$ solid solution and minimum for the $\mathrm{Ti}_{4} \mathrm{AlN}_{3}$ sample and the second parameter is again maximum for the $\mathrm{Ti}_{3} \mathrm{Al}_{0.8} \mathrm{Sn}_{0.2} \mathrm{C}_{2}$ solid solution and minimum for the $\mathrm{Ti}_{3} \mathrm{AlC}_{2}$ sample.

The absolute values of $\sigma_{\mathrm{p}}$ are 1450,1180 and $1130 \mathrm{MPa}$, respectively, for the $\mathrm{Ti}_{3} \mathrm{Al}_{0.8} \mathrm{Sn}_{0.2} \mathrm{C}_{2}$ solid solution, the $\mathrm{Ti}_{3} \mathrm{AlC}_{2}$ and $\mathrm{Ti}_{4} \mathrm{AlN}_{3}$ samples.

\subsection{Microstructure of deformed materials}

\subsubsection{SEM and AFM observations}

Figures 4-6 show scanning electron micrographs of the $\mathrm{Ti}_{3} \mathrm{AlC}_{2}, \mathrm{Ti}_{3} \mathrm{Al}_{0.8} \mathrm{Sn}_{0.2} \mathrm{C}_{2}$ and $\mathrm{Ti}_{4} \mathrm{AlN}_{3}$ deformed surface, respectively. For $\mathrm{Ti}_{3} \mathrm{AlC}_{2}, \mathrm{Ti}_{3} \mathrm{Al}_{0.8} \mathrm{Sn}_{0.2} \mathrm{C}_{2}$ and $\mathrm{Ti}_{4} \mathrm{AlN}_{3}$, the whole samples are plastically deformed. Nevertheless, one can notice, as shown as an example in Figure $4 \mathrm{a}$ obtained on a $\mathrm{Ti}_{3} \mathrm{AlC}_{2}$ sample, that a most damaged region is 

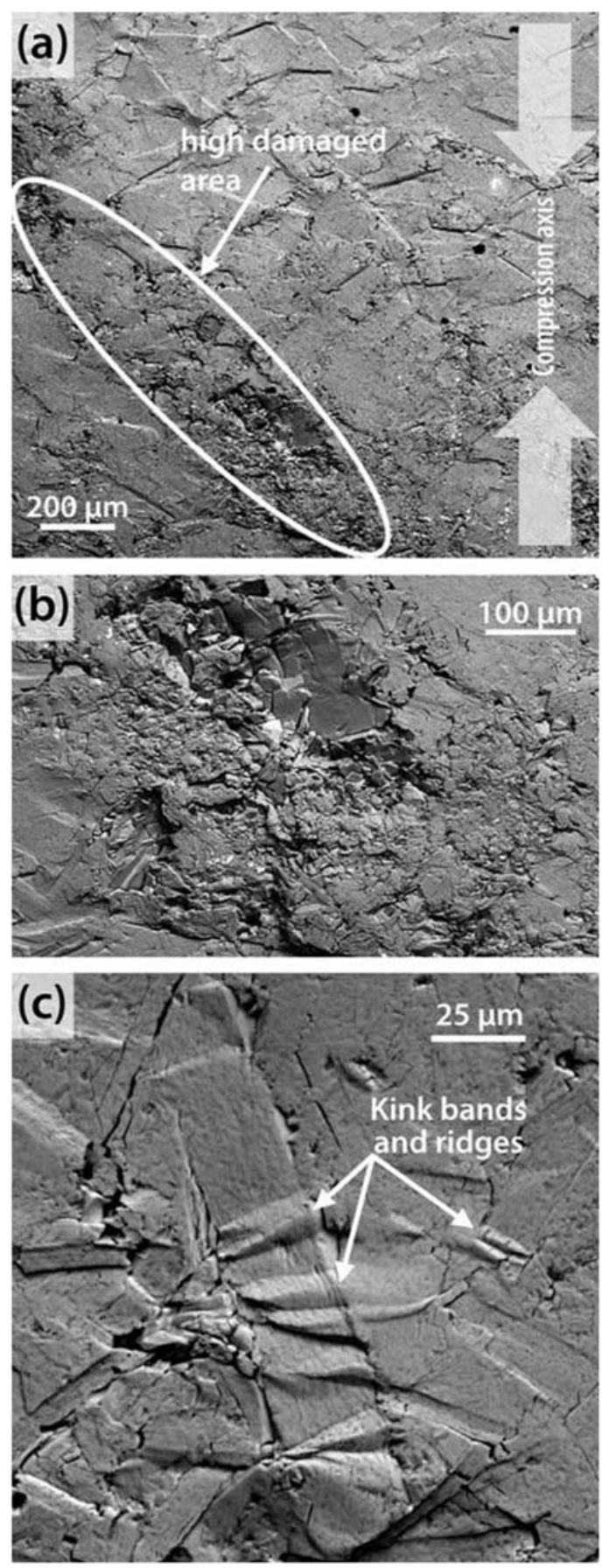

Figure 4. The SEM micrographs of the $\mathrm{Ti}_{3} \mathrm{AlC}_{2}$ deformed surface. (a) General features of deformed surface, the 'most damaged' area is marked with ellipsoid; (b) enlarged image of the 'most damaged' area shown in (a); and (c) a series of kink bands in one lamellar grain. 



Figure 5. The SEM images of the $\mathrm{Ti}_{3} \mathrm{Al}_{0.8} \mathrm{Sn}_{0.2} \mathrm{C}_{2}$ deformed surface. (a) Most damaged area, (b) Intragranular fractures, (c) intergranular cracks, (d) kink bands and (e) ridges.

localized along a direction which makes an angle of about $45^{\circ}$ from the compression axis. It has also to be noticed, by comparing Figures $4 \mathrm{~b}, 5 \mathrm{a}$ and $6 \mathrm{a}$, that the most damaged region of the solid solution sample (Figure 5a) is less damaged than its counterpart in $\mathrm{Ti}_{3} \mathrm{AlC}_{2}$ (Figure $4 \mathrm{~b}$ ) and $\mathrm{Ti}_{4} \mathrm{AlN}_{3}$ (Figure 6a) samples. In the most damaged area, the microstructure of the deformed samples mainly shows intragranular fractures (see Figures $5 \mathrm{~b}$ and 6b), kink band and ridge formations (see Figures 4c, 5d, e and 6c) which are usually associated to dislocation walls in hexagonal structure materials [29]. In the less damaged area, the microstructure of the deformed samples mainly shows intergranular cracks (see Figure 5c). In Figure 5d and e, cracks are not observed within the $\mathrm{Ti}_{x} \mathrm{Al}_{y}$ intermetallics present in the grain boundaries.

Figure $7 \mathrm{a}$ and $\mathrm{b}$ presents AFM observations of the local surface deformation in $\mathrm{Ti}_{3} \mathrm{AlC}_{2}$, the grain organization is schematized in Figure $7 \mathrm{c}$. Two large ridges, of about $400 \mathrm{~nm}$ in height, divide the grain B in three regions. These two ridges propagate across grain $\mathrm{B}$ and generate local surface deformation in the neighbour grain $\mathrm{C}$. It must be noticed that during HIP synthesis process, MAX phase grains usually grow as platelets with surfaces parallel to the basal plane. For this reason, when grains present a rectangular shape on the surface with a high aspect ratio, like grains A and B in Figure 7, their basal planes are close to edge-on orientation. In that case, the formation of the 

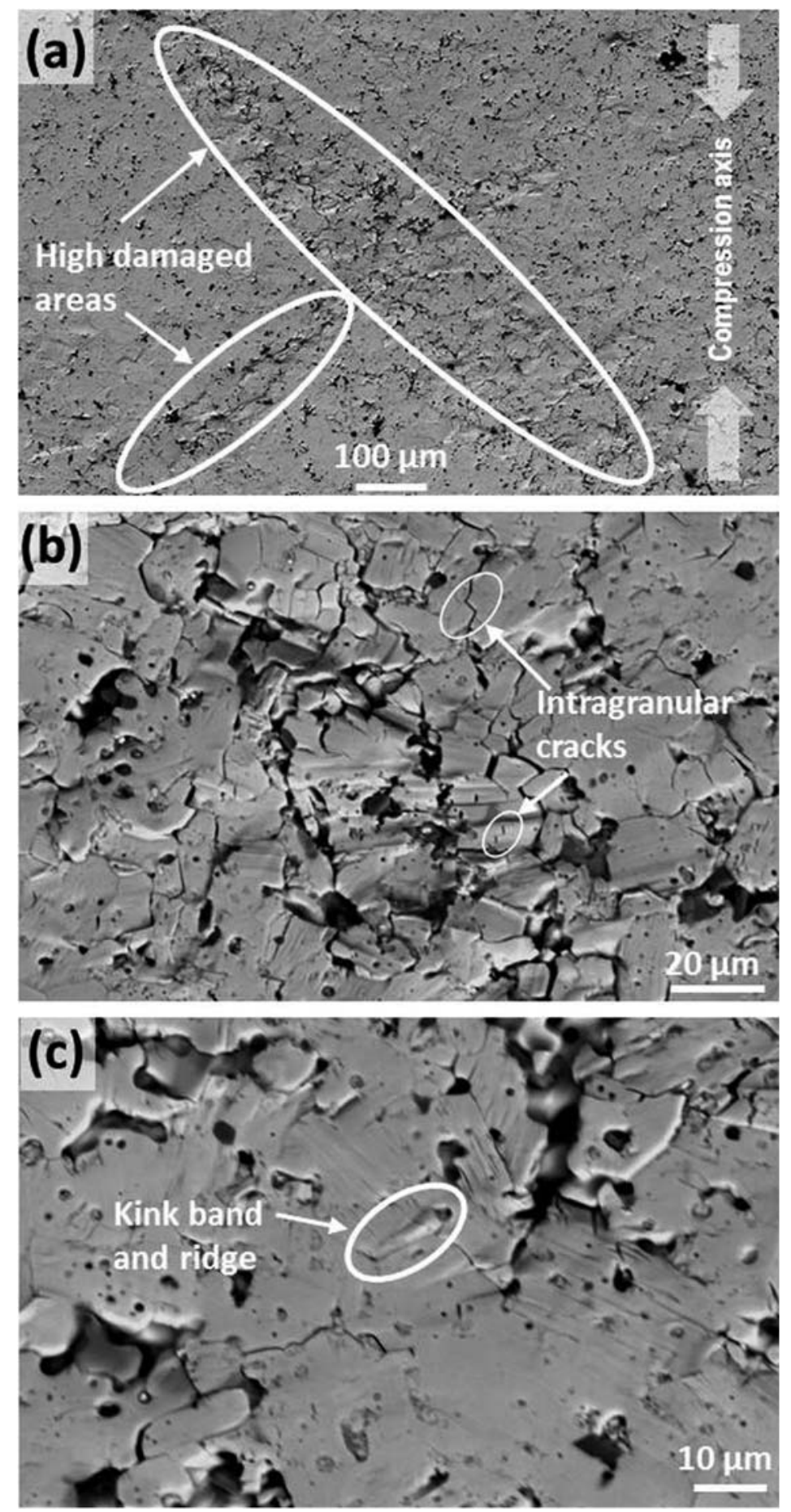

Figure 6. The SEM images of the $\mathrm{Ti}_{4} \mathrm{AlN}_{3}$ deformed surface. (a) most damaged area, (b) inter/ intragranular cracks and delamination and (c) kink band and ridge. 


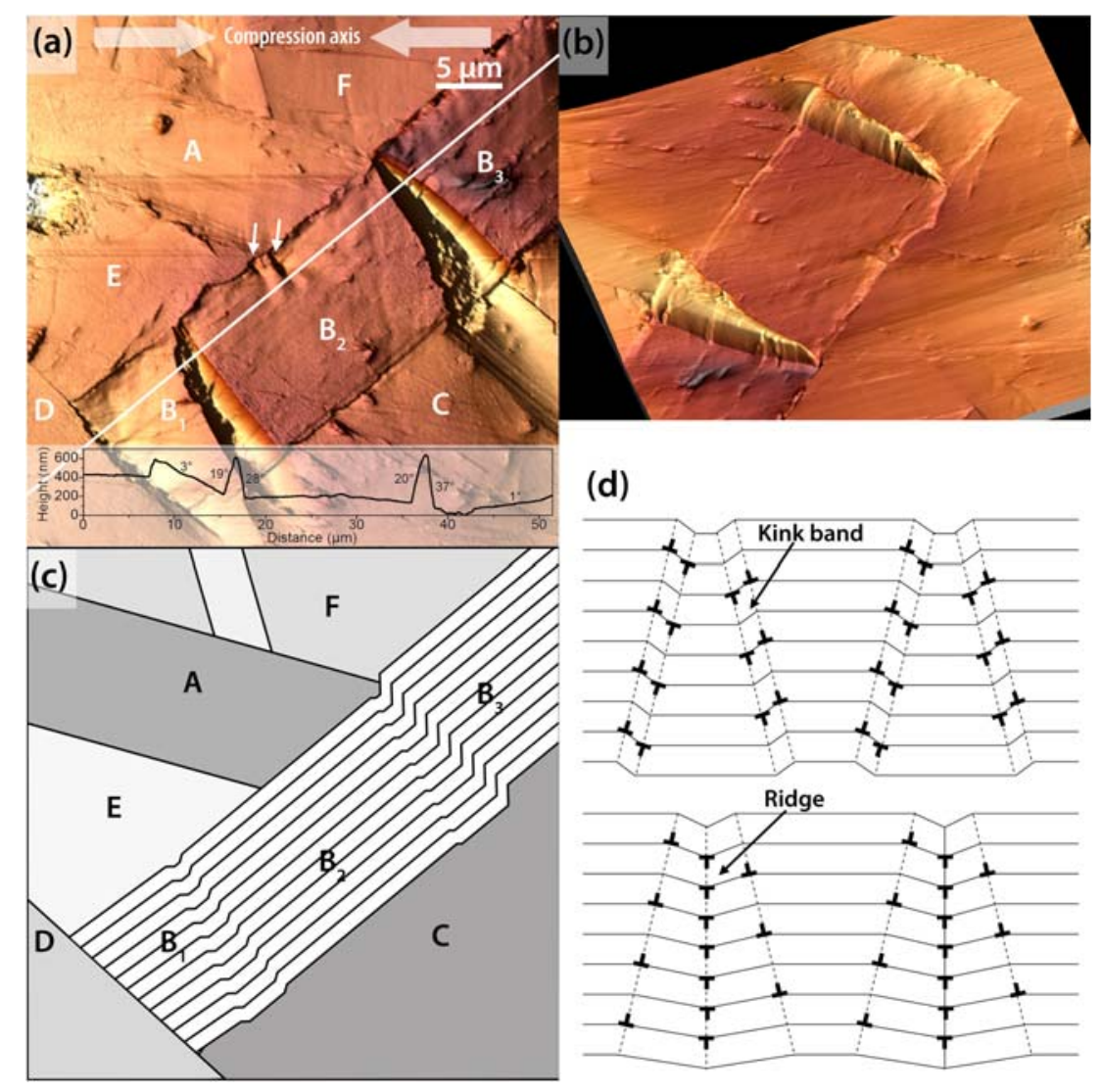

Figure 7. (colour online) (a) and (b) AFM 3D topography image of the $\mathrm{Ti}_{3} \mathrm{AlC}_{2}$ deformed surface for two different image orientations: several ridges are observed in grain B, (c) schematic of the grain arrangement and (d) schematic of the ridge formation from dislocation wall gliding.

two ridges in grain B can be easily explained. This kind of deformation is well known in hexagonal crystal structure [29], and is associated to the formation of two kink bands, each one composed of pairs of dislocations with opposite Burgers vector organized in walls perpendicular to the basal plane, as shown schematically in Figure $7 \mathrm{~d}$. Under the applied stress, the two central dislocation walls of identical Burgers vector can merge into a single dislocation wall, as shown in Figure $7 \mathrm{~d}$. This tilt boundary extends out to a sharp ridge on the surface.

In the AFM cross-section of Figure 7a, the lateral parts B1 and B3 show a slope of few degrees, so that the central part B2 is horizontal but is lying slightly below the rest of the sample. As the surface has been carefully polished before deformation, this depression suggests that the tilt axis associated to the two large ridges is not perpendicular to the surface.

The ridge between $\mathrm{B} 2$ and $\mathrm{B} 3$ starts at the corner of grain A which is in contact with grain B. According to the elastic contact theory, and considering that the basal plane orientation is close to the grain boundary between $\mathrm{A}$ and $\mathrm{B}$, the shear stress in 
the basal plane is maximum within this contact area region. In the same manner, two small ridges, indicated by two white arrows in Figure $7 \mathrm{a}$, are observed at the second corner of the grain A. This configuration, i.e. large ridges initiating from the contact boundary of a neighbour grain, has been observed in many different grains. These observations evidence the effects of the polycrystalline nature of the samples with complex strain fields between neighbouring grains. In addition, the high aspect ratio of grains leads to local stress concentration that disrupts the course of plasticity.

\subsubsection{TEM on deformed materials}

In all samples, the RT-deformed microstructure shows an unambiguous increase of dislocation density compared to the as-grown samples. Figure 8a shows a characteristic example of a $\mathrm{Ti}_{3} \mathrm{Al}_{0.8} \mathrm{Sn}_{0.2} \mathrm{C}_{2}$ deformed microstructure. For the observed grain, the basal plane is at $40^{\circ}$ from the thin foil plane that was cut at $45^{\circ}$ from the compression axis. In the used diffraction condition, the basal plane is perpendicular to the electron beam. Figure 8a gives evidence of an important increase of dislocation pile-up density (inside dashed black ellipse). Dislocation walls (inside black ellipse) are also observed but the increase of their density, compared to the as-grown samples, is not obvious.
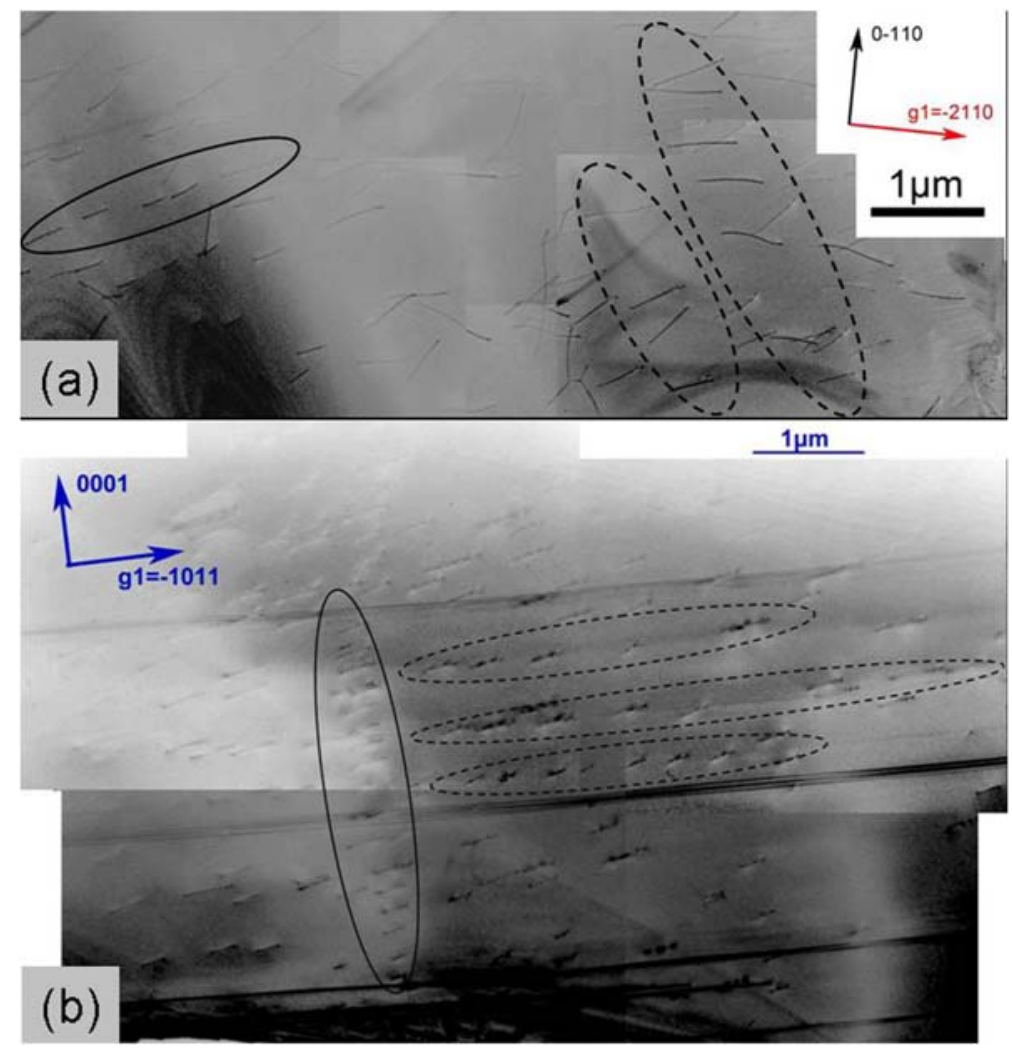

Figure 8. (colour online) The TEM observation of RT-deformed (a) $\mathrm{Ti}_{3} \mathrm{Al}_{0.8} \mathrm{Sn}_{0.2} \mathrm{C}_{2}$ and (b) $\mathrm{Ti}_{3} \mathrm{AlC}_{2}$ grains. Dashed ellipse: dislocation pile-ups, black ellipse: dislocation walls. 


\section{(a)}

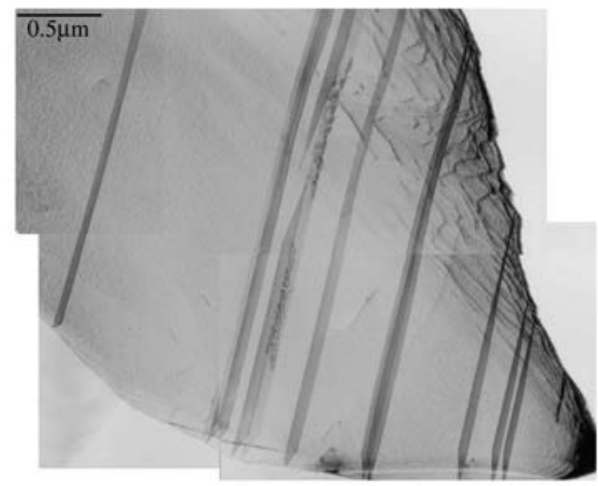

(c)



(b)

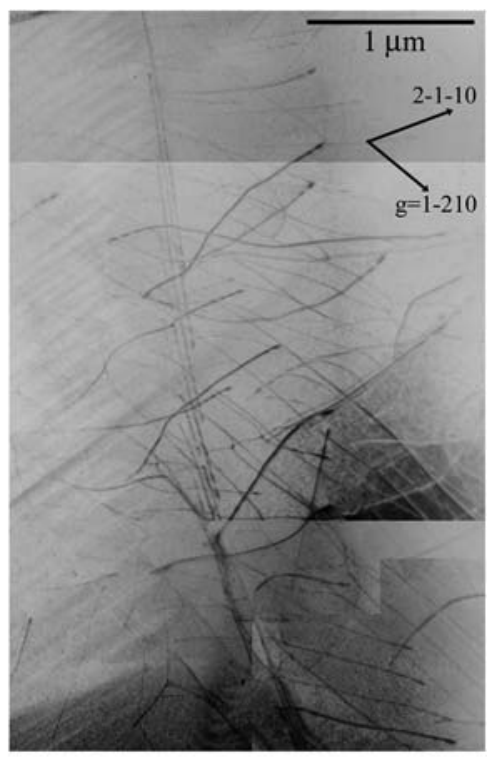

Figure 9. The TEM observation of RT-deformed $\mathrm{Ti}_{4} \mathrm{AlN}_{3}$ grains. (a) Hard grain without any dislocation activity, (b) soft grain with a high density of dislocation (see text) and (c) soft grain showing that dislocation density may become very high leading to entanglement (see text).

Figure $8 \mathrm{~b}$ presents a micrograph of the RT-deformed $\mathrm{Ti}_{3} \mathrm{AlC}_{2}$ microstructure. Again, the increase of the dislocation density is clear, the dislocations being, in their large majority, organized in specific configurations. In the present diffraction conditions, the electron beam is parallel to the basal planes. A very large density of pile-ups is observed in parallel $\left(\begin{array}{llll}0 & 0 & 0 & 1\end{array}\right)$ planes (inside dashed black ellipse) as well as a dislocation wall (inside black ellipse). It has to be pointed out that these walls contain a very low dislocation density. Figure $8 \mathrm{a}$ and $\mathrm{b}$ shows similar configurations observed along two different orientations.

Figure $9 \mathrm{a}$ and $\mathrm{b}$ presents micrographs of two grains, in the same thin foil of the RTdeformed $\mathrm{Ti}_{4} \mathrm{AlN}_{3}$. The two grains have different orientations with respect to the compression axis direction: the basal plane of the grain shown in Figure 9a is almost perpendicular to the thin foil plane when it is parallel to the thin foil plane for the grain shown in Figure 9b. Comparison of the two micrographs shows an obvious difference in dislocation activity. Figure 9a presents a grain with long SFs similar to the ones observed in the as-grown material [19]. Only few isolated dislocations are observed. In this grain, the defect density (dislocation or SF) remains similar to the density observed in the as-grown $\mathrm{Ti}_{4} \mathrm{AlN}_{3}$. Figure $9 \mathrm{~b}$ shows a grain for which the basal plane is parallel to the thin foil. The grain presents a very high dislocation density much larger than in the as-grown material, no SFs being observed. All dislocations are lying in the basal plane. A wall is visible but the majority of dislocations belongs to a pile-up with contrasts consistent with Burgers vector $\vec{b}=1 / 3\langle 2 \overline{1} \overline{1} 0\rangle$. At least three families of pile-ups are distinguished with different dislocation's line directions, shape and density. A first 
family presents very long and straight dislocation segments parallel to [1릴 with a Burgers vector equal to $\frac{1}{3}[2 \overline{1} \overline{1} 0]$ that corresponds to a mixed character. The other fami-

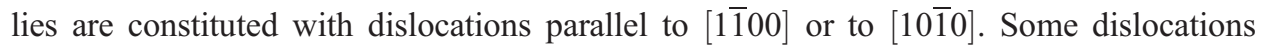
may exhibit changes of their direction along their length and may be parallel to [1010] or to $[3 \overline{1} \overline{2} 0]$. Interactions between dislocations of different pile-ups are clearly observed, their exact nature being, however, not resolved. In particular, it is not clear if the dislocations are lying in the same plane and interact via nodes or not. Figure $9 \mathrm{c}$ gives another example of very high dislocation density observed in the case of RT-deformed $\mathrm{Ti}_{3} \mathrm{AlC}_{2}$. The $\mathrm{Ti}_{3} \mathrm{AlC}_{2}$ grain orientation is very close to the one of the $\mathrm{Ti}_{4} \mathrm{AlN}_{3}$ grain presented in Figure 9b. Long dislocations lying in the basal plane are observed, these dislocations belong to different pile-ups. Moreover a very dense dislocation entanglement is observed. Here, again, the very large density does not allow for determining the exact nature of the numerous dislocation interactions. In all samples, the SF density
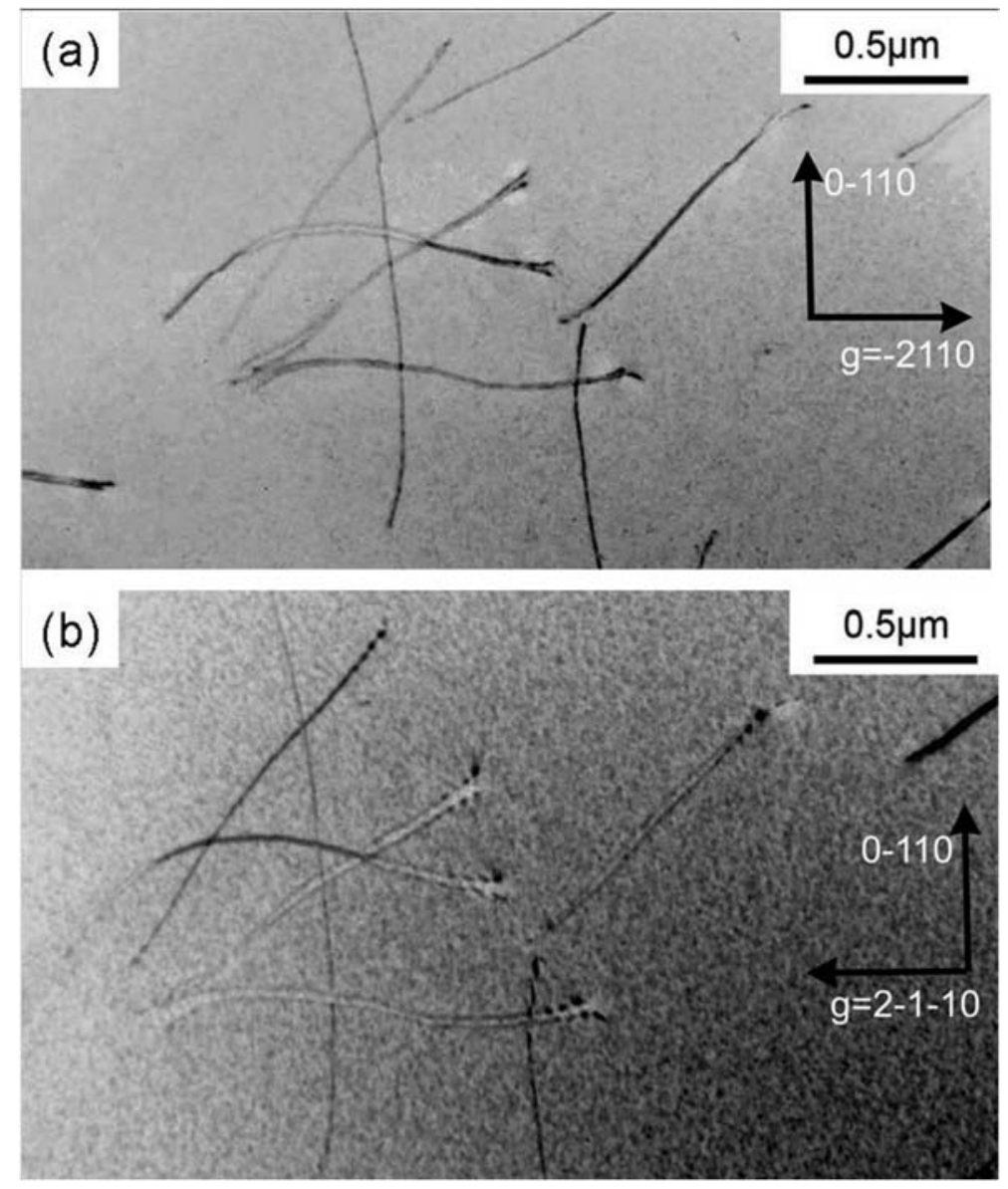

Figure 10. The TEM observation of RT-deformed $\mathrm{Ti}_{3} \mathrm{Al}_{0.8} \mathrm{Sn}_{0.2} \mathrm{C}_{2}$ grain obtained with two opposite diffraction vectors: (a) $g_{1}=-2110$ and (b) $g_{2}=-g_{1}=2-1-10$. 
remains similar to the one observed in as-grown materials. Figure 10 shows a dislocation configuration observed in $\mathrm{Ti}_{3} \mathrm{Al}_{0.8} \mathrm{Sn}_{0.2} \mathrm{C}_{2}$ with two different $\mathrm{g}$ vectors, respectively, with $g_{1}=-2110$ and $g_{2}=-g_{1}=2-1-10$ diffraction vectors. Comparing both images, we clearly observe different distances between the dislocation contrasts. Such feature is characteristic of dislocation dipoles. The dislocation dipoles are lying in the basal plane. Actually, dislocation dipoles are observed in many grains of $\mathrm{Ti}_{3} \mathrm{Al}_{0.8} \mathrm{Sn}_{0.2} \mathrm{C}_{2}$ and were also observed in deformed $\mathrm{Ti}_{2} \mathrm{AlN}$ [20].

\section{Discussion and conclusion}

The use of the Paterson apparatus enabled to probe plasticity in the present MAX phases at temperature where they generally exhibit a brittle-like behaviour: massive cracking is usually observed in samples deformed at RP and RT when trying to reach large strain $[9,30]$. Without this pressure, all the samples would exhibit progressive cracking, if not sudden brittle rupture, at stresses lower than the ones reached here. Even low strain rate experiments at RP cannot prevent for the brittle behaviour of most of the MAX phases [31]. The present results are, therefore, very characteristic of the macroscopic plastic deformation of polycrystalline MAX samples; in other words, the deep plasticity regime could be probed and the observed deformed microstructures are, therefore, representative of all possible deformation mechanisms when an assembly of MAX grains (with various size and shape) are forced to plastically deform together without the possibility to relax energy by fracture. The obtained $\sigma_{\mathrm{P}}$ values are to be compared with literature data: the maximum compressive strength reported at RT-RP approaches $1 \mathrm{GPa}$ in the model MAX phase $\mathrm{Ti}_{3} \mathrm{SiC}_{2}$ [9,30,32] and in $\mathrm{Cr}_{2} \mathrm{AlC}$ [33]; it is in the range 700-950 $\mathrm{MPa}$ for $\mathrm{Ti}_{3} \mathrm{SiC}_{2}$ [34]. Wang et al. performed compressive tests at a strain rate of $10^{-4} \mathrm{~s}^{-1}$ in air for polycrystalline $\mathrm{Ti}_{3} \mathrm{AlC}_{2}$ ceramics and reached a compressive strength of $800 \mathrm{MPa}$ [31]. There are no available data for the $\mathrm{Ti}_{3} \mathrm{Al}_{0.8} \mathrm{Sn}_{0.2} \mathrm{C}_{2}$ solid solution and the $\mathrm{Ti}_{4} \mathrm{AlN}_{3}$ phase. Noteworthy, in RP condition, most of the compression tests are associated to early brittle failure predominantly characterized by intergranular cracking: only the rise of temperature above $600{ }^{\circ} \mathrm{C}$ generally enables to reach significant plastic deformation in MAX phases. Wang et al. observe failure of $\mathrm{Ti}_{3} \mathrm{AlC}_{2}$ below $1000^{\circ} \mathrm{C}$, plastic deformation occurs above $1050{ }^{\circ} \mathrm{C}$. Moreover, the mechanical data are extremely dependent on microstructure in particular of the grain size $[35,36]$. It is, therefore, not straightforward to compare the literature data with the present results where the confining pressure suppresses the brittle failure at RT to the profit of plasticity. However, the present result brings new elements to the understanding of deformation mechanism of a polycrystalline MAX sample when subjected to the different stages of compression, i.e. experiencing the elastic, plastic and damage regimes.

In detail, for the $\mathrm{Ti}_{3} \mathrm{Al}_{0.8} \mathrm{Sn}_{0.2} \mathrm{C}_{2}$ sample, a plastic strain larger than $3 \%$ could be reached without brittle rupture, this value being even larger $(\sim 6 \%)$ for $\mathrm{Ti}_{3} \mathrm{AlC}_{2}$. Nevertheless, the strain hardening and maximum stress of $\mathrm{Ti}_{3} \mathrm{Al}_{0.8} \mathrm{Sn}_{0.2} \mathrm{C}_{2}$ are higher than those of $\mathrm{Ti}_{3} \mathrm{AlC}_{2}$ despite identical deformation conditions. Earlier work has demonstrated that solid solution strengthening is not operative by incorporation of $\mathrm{Al}$ into the $\mathrm{Ti}_{3} \mathrm{SnC}_{2}$ structure [37]: the presence of small lamellas and the presence of a higher content of ductile $\mathrm{Ti}_{x} \mathrm{Al}_{y}$ intermetallics distributed in the grain boundaries are, therefore, the main contributors to the observed enhancement of compressive strength. Maximum 
stress is lower for the $\mathrm{Ti}_{4} \mathrm{AlN}_{3}$ phase. Although comparison between different MAX systems is difficult, it is worth noting that all tested MAX samples present similar stress-strain curve shape, with a hardening regime and subsequent softening regime.

In all deformed samples, SEM observations show a localized deformation region exhibiting intergranular and intragranular cracks as well as kink bands and delamination that are characteristic of deformed MAX phases like $\mathrm{Ti}_{3} \mathrm{SiC}_{2}[13,36]$ and $\mathrm{Cr}_{2} \mathrm{AlC}$ [31]. It has to be noticed that the most deformed area is less damaged in the deformed $\mathrm{Ti}_{3} \mathrm{Al}_{0.8} \mathrm{Sn}_{0.2} \mathrm{C}_{2}$ solid solution than in the stoichiometric $\mathrm{Ti}_{3} \mathrm{AlC}_{2}$ or $\mathrm{Ti}_{4} \mathrm{AlN}_{3}$ phases. If authors often report intergranular cracks, intragranular ones are also observed [30]. Detailed investigation shows that cracks do not propagate in the $\mathrm{Ti}_{x} \mathrm{Al}_{y}$ intermetallics. One can assume that this additional ductile phase inhibits crack propagation especially in the $\mathrm{Ti}_{3} \mathrm{Al}_{0.8} \mathrm{Sn}_{0.2} \mathrm{C}_{2}$ solid solution where its content is slightly more important than in the $\mathrm{Ti}_{3} \mathrm{AlC}_{2}$ phase. As a consequence, the presence of a small amount of $\mathrm{Ti}_{x} \mathrm{Al}_{y}$ impurity may play an important role in the enhancement of strain hardening and maximum stress in $\mathrm{Ti}_{3} \mathrm{Al}_{0.8} \mathrm{Sn}_{0.2} \mathrm{C}_{2}$ compared to $\mathrm{Ti}_{3} \mathrm{AlC}_{2}$ and $\mathrm{Ti}_{4} \mathrm{AlN}_{3}$ samples. From the observation of massive cracking, it can be suggested that the softening regime is associated to the damage production while the sample integrity is maintained by the applied hydrostatic pressure. In other words, this regime may rarely be observed in RP conditions where cracking leads to the early failure of the samples.

AFM observations give evidence of local stress concentration on specific grains which are thus highly plastically deformed. This stress concentration is due to the elastic anisotropy of MAX phases, combined to the high aspect ratio of grains. It results in nucleation of kink bands forming ridges localized at the surface. The local strain associated to the kink bands concentrates stress at the extremities of the ridges located at grain boundary. In turn, this local stress concentration induces local plastic deformation in the neighbour grain. In other words, due to their respective shape and orientation relative to the compression axis, some grains may act as a local hard obstacle or a soft transmitter to the percolation of deformation from grain to grain.

The TEM observations performed on as-grown Ti-Al-C MAX system show very classical microstructure for MAX phases with low dislocation density organized in wall or in pile-ups and SFs. In particular, the observations of $\mathrm{Ti}_{3} \mathrm{AlC}_{2}$ are quite similar to the micrograph obtained by Wang et al. [29] on $\mathrm{Ti}_{3} \mathrm{AlC}_{2}$ prepared by solid-liquid reaction, the dislocation density being, however, lower in the MAX phase obtained here by powder metallurgy. Concerning the SFs, it is worth noting that their contrast is very similar to the one analysed in as-grown $\mathrm{Ti}_{4} \mathrm{AlN}_{3}[19]$.

The TEM observations of RT-deformed $\mathrm{Ti}_{3} \mathrm{AlC}_{2}$ or $\mathrm{Ti}_{3} \mathrm{Al}_{0.8} \mathrm{Sn}_{0.2} \mathrm{C}_{2}$ solid solution show unambiguously that plastic deformation is accompanied by an increase of dislocation density. This result is well known in the most studied MAX phase, $\mathrm{Ti}_{3} \mathrm{SiC}_{2}$, both in coarse and fine grain materials deformed at high temperature [36] or macrograined samples deformed at RT [11]. In all cases, dislocations are confined into the basal plane and organized either in walls or in pile-ups. Moreover, plastic anisotropy has been observed in $\mathrm{Ti}_{3} \mathrm{SiC}_{2}$ by electron backscattered diffraction after creep at high temperature [36] and is consistent with stress-strain curves obtained at high temperature in highly oriented $\mathrm{Ti}_{3} \mathrm{SiC}_{2}$ macrograined [13]. In the deformed $\mathrm{Ti}-\mathrm{Al}-\mathrm{C}$ grains presented in this work, the basal plane is neither perpendicular nor parallel to the compression axis. In such grains, for the stoichiometric phase as well as for the solid solution, dislocation walls and pile-ups coexist in same grains, probably as a result of deep plasticity 
imposed to the sample in the Paterson apparatus. In literature and in $\mathrm{Ti}_{3} \mathrm{SiC}_{2}$, walls and pile-ups rarely coexist. [11,36]. The deformed small-grained $\mathrm{Ti}_{4} \mathrm{AlN}_{3}$ sample allows for investigating microstructures with many orientations according to the compression axis. The TEM observations of different grains show actually that dislocation activity highly depends on the grain orientation: some grains are dislocations-free when some present a very high dislocation density. In these grains, different dislocation pile-ups are shown to interact with each other, the nature of the interactions being here not resolved. Actually, when pile-ups lie in the same $\left(\begin{array}{llll}0 & 0 & 0 & 1\end{array}\right)$ plane and if dislocations have different Burgers vectors, then the interactions lead to the formation of dislocation nodes. If pile-ups lie


tion of dislocation entanglement confirms that dislocations may be organized in such configuration so that their glide in the basal plane will be difficult, as observed in $\mathrm{Ti}_{2} \mathrm{AlN}[20]$.

In summary, the presented original combination of multiscale characterization techniques, from microscopic to macroscopic dimensions, provides a unique insight into all the length scales of the plastic deformation mechanisms; in particular, the effect of the mesoscale, i.e. the grain arrangement in a highly anisotropic polycrystal. The polycrystalline nature of the samples is expected to locally lead to more complex stress states than the imposed macroscopic uniaxial compression due to 'inter-granular stress' concentration at grain boundaries, leading to the percolation of plastic deformation from grain to grain along specific paths. The results presented here, added to the fact that plasticity is confined to basal planes, suggest that both crystallographic orientation and local environment induce a typical behaviour with 'hard' and 'soft' grains that deform by dislocation glide to different plastic levels. It is shown here that soft grains present a very high dislocation density with different dislocation families. In such grains, dislocations are organized in complex configurations with interactions and reactions, changes of line direction and formation of tangles that are far from the simple picture of dislocations gliding in parallel planes without interactions. The direct consequence is the absence of simple isolated dislocation walls that are closely related to the formation and arrest of intragranular delamination or crack [38].

A first scenario can, therefore, be proposed for the specific case of deformation behaviour of MAX phases under hydrostatic pressure (where deep plasticity can be reached): plasticity is initiated by the nucleation of dislocations from various sources (including from grain boundaries as an effect of neighbouring grains). These dislocations interact and form complex networks, far from simple dislocation walls, that induce a hardening regime. When further deformation is applied, intergranular cracks nucleate ('weakest link' effect) and percolate leading to the start of a softening regime. Finally, after copious plasticity and intergranular cracking, and here because of hydrostatic pressure, intragranular cracks form and lead to the localization of damage (zero hardening). Noteworthy, the last stage is very unlikely to be observed during deformation tests performed at RP.

\section{References}

[1] W. Jeitschko and H. Nowotny, Monatshefte für Chemie 98 (1967) p.329.

[2] W. Jeitschko, H. Nowotny and F. Benesovsky, Monatshefte für Chemie 94 (1963) p.672.

[3] W. Jeitschko, H. Nowotny and F. Benesovsky, Monatshefte für Chemie 95 (1964) p.431. 
[4] H. Wolfsgruber, H. Nowotny and F. Benesovsky, Monatshefte für Chemie 98 (1967) p.2403.

[5] H. Nowotny, Prog. Solid State Chem. 5 (1971) p.27.

[6] M.W. Barsoum and T. El-Raghy, J. Am. Ceram. Soc. 79 (1996) p.1953.

[7] M.W. Barsoum, L. Farber, I. Levin, A. Procopio, T. El-Raghy and A. Berner, J. Am. Ceram. Soc. 82 (1999) p.2545.

[8] C.J. Rawn, M.W. Barsoum, T. El-Raghy, A. Procopio, C.M. Hoffmann and C.R. Hubbard, Mater. Res. Bull. 35 (2000) p.1785.

[9] M.W. Barsoum, Prog. Solid State Chem. 28 (2000) p.201.

[10] M.W. Barsoum and M. Radovici in Encyclopedia of Materials Science and Technology, K.H.S Buschow, R.W. Cahn, M.C. Flemings, E.J. Kramer, S. Mahajan and P. Veyssiere, eds., Elsevier, Oxford, 2004.

[11] M.W. Barsoum, L. Farber and T. El-Raghy, Metall. Mater. Trans. A 30A (1999) p.1727.

[12] L. Farber, M.W. Barsoum, A. Zavaliangos and T. El-Raghy, J. Am. Ceram. Soc. 8 (1998) p.1677.

[13] M.W. Barsoum and T. El-Raghy, Metall. Mater. Trans. A 30A (1999) p.363.

[14] B.J. Kooi, R.J. Poppen, N.J.M. Carvalho, J.T.M. De Hosson and M.W. Barsoum, Acta Mater. 51 (2003) p.2859.

[15] F.C. Frank and A.N. Stroh, Proc. Phys. Soc. B 65 (1952) p.811.

[16] M.W. Barsoum, T. Zhen, A. Zhou, S. Basu and S.R. Kalidindi, Phys. Rev. B 71 (2005) p.134101.

[17] M.W. Barsoum, T. Zhen, S.R. Kalidindi, M. Radovic and A. Murugaiah, Nat. Mater. 2 (2003) p.107.

[18] C. Tromas, P. Villechaise, V. Gauthier-Brunet and S. Dubois, Philos. Mag. 91 (2011) p. 1265.

[19] A. Joulain, L. Thilly and J. Rabier, Philos. Mag. 88 (2008) p.1307.

[20] A. Guitton, A. Joulain, L. Thilly and C. Tromas, accepted in Philos. Mag. 92 (2012) p. 4536.

[21] R. Yu, Q. Zhan, L.L. He, Y. Zhou and H.Q. Ye, Philos. Mag. Lett. 83 (2003) p.325.

[22] A. Procopio, M.W. Barsoum and T. El-Raghy, Metall. Mater. Trans. A 31A (2000) p.333.

[23] A. Procopio, T. El-Raghy and M.W. Barsoum, Metall. Mater. Trans. A 31A (2000) p.373.

[24] M. Paterson, Int. J. Rock Mech. Min. Sci. 7 (1970) p.517.

[25] M. Paterson and D.L. Olgaard, J. Struct. Geol. 22 (2000) p.1341.

[26] A. Mussi, J. Rabier, L. Thilly and J.-L. Demenet, Phys. Status Solidi C 4 (2007) p.2929.

[27] A. Mussi, L. Thilly, J. Rabier and J.-L. Demenet, Mater. Sci. Eng., A 478 (2008) p.140.

[28] I. Horcas, R. Fernández, J.M. Gómez-Rodríguez, J. Colchero, J. Gómez-Herrero and A.M. Baro, Rev. Sci. Instrum. 78 (2007) p.013705.

[29] J.B. Hess and C.S. Barett, Met. Trans. 185 (1949) p.599.

[30] Z.F. Zhang and Z.M. Sun, Mat. Sci. Eng. A 408 (2005) p.64.

[31] X.H. Wang and Y. Zhou, Acta Mater. 50 (2002) p.3141.

[32] A.G. Zhou and M.W. Barsoum, Metall. Mater. Trans. A 40A (2009) p.1741.

[33] W. Tian, Z.M. Sun, H. Hashimoto and Y. Du, J. Mater. Sci. 44 (2009) p.102.

[34] Y. Zhou and Z. Sun, Mat. Res. Innovat. 3 (1999) p.171.

[35] T. Zhen, M.W. Barsoum and S.R. Kalidindi, Acta Mater. 53 (2005) p.4163.

[36] F. Barcelo, S. Doriot, T. Cozzika, M. Leflem, J.L. Béchade, M. Radovic and M.W. Barsoum, J. Alloys Compd. 488 (2010) p.181.

[37] S. Dubois, G.P. Bei, C. Tromas, V. Gauthier-Brunet and P. Gadaud, Int. J. Appl. Ceram. Technol. 7 (2010) p.719.

[38] J.M. Molina-Aldareguia, J. Emmerlich, J.P. Palmquist, U. Jansson and L. Hultman, Scr. Mater. 49 (2003) p.155. 